\title{
Aplikasi Program Linear: Media Pembelajaran Berbasis Android Menggunakan MIT App Inventor
}

\author{
Syarifah Sri Rahayu ${ }^{1 *}$, Achi Rinaldi ${ }^{2}$, \& Wawan Gunawan ${ }^{3}$ \\ ${ }^{1,2,3}$ Universitas Islam Negeri Raden Intan Lampung, Bandar Lampung, Indonesia
}

\section{INFO ARTICLES}

Article History:

Received: 28-11-2021

Revised: 28-12-2021

Approved: 28-12-2021

Publish Online: 31-12-2021

\section{Key Words:}

Linear Program; Learning Media; MIT App Inventor;

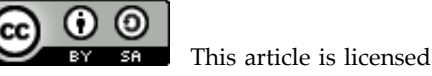

under a Creative Commons AttributionShareAlike 4.0 International License.

\begin{abstract}
Learning media becomes a main thing in determining the quality of learning. The development model needs to be considered to design a learning media to ensure its validity and quality to help smooth learning. The MIT App Inventor-assisted linear program application aims to be developed into a suitable and interesting learning media to use. The development design used in this $R \& D$ (Research and Development) research method is ADDIE which is simplified into $A D D$. The test subjects in this study were tested on 2 media expert validators, 3 material expert validators, individual trials, small group tests, and field trials. Based on the results of data analysis, the linear program application learning media was declared valid and feasible to use with the results of the media expert validator being 3.56 and the material expert validator being 3.86. The average score in the very attractive category in the one to one trial was 3.50, the small group trial was 3.55 , and 3.58 for the field trial.
\end{abstract}

\begin{abstract}
Abstrak: Media pembelajaran menjadi suatu hal yang pokok dalam menetapkan kualitas pembelajaran. Model pengembangan perlu diperhatikan untuk mendesain suatu media pembelajaran guna memastikan kevalidan serta kualitasnya untuk membantu kelancaran pembelajaran. Aplikasi program linear berbantuan MIT App Inventor bertujuan agar dapat dikembangkan menjadi media pembelajaran yang layak serta menarik untuk digunakan. Desain pengembangan yang digunakan pada metode penelitian $R \& D$ (Research and Development) ini adalah ADDIE yang disederhanakan menjadi ADD. Subjek uji coba pada penelitian ini diujikan kepada 2 validator ahli media, 3 validator ahli materi, uji coba perorangan, uji kelompok kecil, uji coba lapangan. Berdasarkan hasil analisis data bahwa media pembelajaran aplikasi program linear dinyatakan valid dan layak digunakan dengan perolehan hasil validator ahli media 3,56 dan validator ahli materi 3,86. Skor rata-rata dalam kategori sangat menarik pada uji coba perorangan sebesar 3,50, uji coba kelompok kecil 3,55, dan 3,58 untuk uji coba lapangan.
\end{abstract}

Correspondence Address: Jl. Z.A. Pagar Alam, Gg. Dakwah II No. 36B, Labuhan Ratu, Kota Bandar Lampung, Lampung, Indonesia, Kode Pos 35142; e-mail: syarifahsrirahayu@gmail.com

How to Cite (APA $6^{\text {th }}$ Style): Rahayu, S.S., Rinaldi, A., \& Gunawan, W. (2021). Aplikasi Program Linear: Media Pembelajaran Berbasis Android Menggunakan MIT App Inventor. JKPM (Jurnal Kajian Pendidikan Matematika), 7(1): 107-120. http://dx.doi.org/10.30998/jkpm.v7i1.11442

Copyright: 2021 Syarifah Sri Rahayu, Achi Rinaldi, Wawan Gunawan

Competing Interests Disclosures: The authors declare that they have no significant competing financial, professional or personal interests that might have influenced the performance or presentation of the work described in this manuscript. 


\section{PENDAHULUAN}

Berkembang dan majunya suatu negara dengan ilmu pengetahuan dan teknologi (IPTEK) adalah dua hal yang saling bersangkutan (Malenda, et. al., 2019). IPTEK yang dimanfaatkan guna mempermudah pengolahan dan pengembangan di berbagai lingkup bernegara seperti ranah ekonomi, sosial, politik, keamanan dan pertahanan, kehidupan umat beragama, hingga pendidikan. Perkembangan teknologi informasi ini terjadi fenomena yang dibilang cukup menarik, dimana perkembangan pengguna gadget menjalar di berbagai kalangan masyarakat sejalan dengan ilmu pengetahuan teknologi yang semakin pesat. Selaras dengan fungsinya yang membuat jalinan komunikasi dan informasi yang lebih efisien, cepat, dan mudah gadget atau gawai sendiri merupakan alat canggih yang dapat menyuguhkan bermacam berita hingga seluruh dunia, laman bermedia sosial, hiburan, dan juga hobi. Kecanggihan gadget sendiri juga digunakan oleh orang-orang yang berkepentingan di dunia bisnis, pekerja kantor maupun universitas, hingga pekerjaan tugas dan pemahaman materi-materi dapat dilakukan menggunakan alat ini (Marpaung, 2018).

Dunia pendidikan di masa modern saat ini IPTEK sangat memiliki andil yang besar bagi tenaga pengajar dan peserta didik dari tingkat sekolah dasar maupun hingga tingkat lingkup universitas. Kemajuan dunia pendidikan haruslah berbanding lurus terhadap majunya teknologi (Wiratomo \& Mulyatna, 2020). Penggunaan teknologi khususnya dalam media pembelajaran diharapkan dapat sangat membantu proses pemahaman dan tumbuh kembang berpikir siswa dalam mempelajari isi-isi dari mata pelajaran. Proses pemahaman siswa ini baik saat dilakukan pembelajaran tatap muka langsung di sekolah bersama guru maupun belajar mandiri di luar sekolah (Safitri, et. al., 2020).

Media pembelajaran adalah media yang diterapkan pada pembelajaran dapat berupa perangkat lunak maupun keras, lingkungan dan bermacam bentuk kegiatan sehingga terciptanya komunikasi antara guru dan siswa dalam kegiatan pembelajaran demi terwujudnya tujuan pembelajaran yang ingin dicapai (Tafonao, 2018). Pemilihan metode atau media yang akan diterapkan inilah yang akan menentukan keberhasilan guru dalam pembelajaran. Penggunaan media pembelajaran dapat mempengaruhi tingkat motivasi, komunikasi dan interaksi belajar siswa guna lebih interaktif dalam kegiatan belajar mengajar (Lestari, 2018; Mustaqim, 2016; Apriliyani \& Mulyatna, 2021). Maka kemajuan teknologi dalam bidang pendidikan dapat menunjang dalam pembuatan media pembelajaran yang menarik sehingga dapat mengurangi dampak negatif dari kecanggihan teknologi di arus globalisasi saat ini (Septiyani \& Apriyanto, 2019)

Terdapat berbagai fasilitator dalam pembuatan media pembelajaran dalam hal ini untuk membuat media pembelajaran berbentuk aplikasi. Salah satu fasilitator web terbuka penyedia pembuatan aplikasi yaitu App Inventor 2 (AI2). AI2 yaitu IDE (Integrated Development Environment) dengan kedudukan generasi ke-2 dari App Inventor yang dikendalikan Massachusetts Institute of Technology (MIT). AI2 berdasarkan pada cloud yang dapat dicapai melalui internet browser. AI2 menggunakan block puzzle yang dapat disusun dan dijadikan serangkaian kode (Wihidayat \& Maryono, 2017). Terdapat berbagai keunggulan dan kelebihan menggunakan App Inventor yaitu kemudahannya dalam pemrograman karena user tidak harus mempunyai pengetahuan mendasar pada programmer, mengerti dan paham kode, atau memiliki pengalaman di dunia Information Technology (IT). Hal penting ketika membuat aplikasi memakai App Inventor ialah bagaimana ketika programmer memainkan logikanya serta bernalar layaknya saat seseorang memasang teka-teki (Syaputrizal \& Jannah, 2019).

MIT App Inventor sendiri memiliki kelebihan dan kekurangan sebagai aplikasi pembangun. Kelebihannya antara lain disediakannya blok kode yang hanya perlu kita susun dan tidak menuliskan kode-kode program yang terbilang rumit, hanya perlu drag and drop komponen yang diperlukan dalam perancangan aplikasi, dalam pengujian aplikasi disediakan tiga pilihan yaitu menggunakan emulator, Wi-Fi, maupun kabel USB. Tidak luput dari kekurangan MIT App Inventor antara lain aplikasi yang berbasis web sehingga jika menggunakannya dalam merancang aplikasi agar 
tersambung dengan internet, user harus pandai dalam merancang tampilan sendiri agar tampilan aplikasi menarik, belum didukungnya pembuatan aplikasi untuk pengguna iPhone (Komputer, 2013; Mulyana, 2012).

Beragam kelebihan yang dimiliki MIT App Inventor membuat para perancang tidak sedikit menggunakannya dalam pembuatan beragam aplikasi android. Seperti yang telah peneliti sebelumnya lakukan, MIT App Inventor bisa digunakan dalam pembuatan berbagai kepentingan seperti games bola tangkis untuk android, aplikasi E-business Cooperation android sehingga multiprodusen dapat memasarkan serta mengontrol barang-barang produksi, aplikasi kamus akuntansi, dan juga pada bidang pendidikan (Hasan, et. al., 2017; Yaqin \& Al Anis, 2019). Bidang pendidikan khususnya lingkup matematika sendiri telah banyak mengembangkan MIT App Inventor sebagai penunjang dalam kegiatan pembelajaran. Beragam materi matematika telah dibuat versi aplikasi android seperti barisan dan deret, trigonometri, aljabar, geometri, sistem operasi, dan fungsi komposisi (Angriani, et. al., 2020; Ekiningsih, et. al., 2019; Fitri, et. al., 2021; Hakky et. al., 2018; Negara, et. al., 2019). Sekian banyak materi belum ditemukannya pembaruan pada materi program linear untuk tingkat SLTA. Maka peneliti memutuskan untuk mengembangkan aplikasi media pembelajaran materi program linear berbantuan MIT App Inventor untuk android.

\section{METODE}

Research and Development $(\mathrm{R} \& \mathrm{D})$ adalah metode penelitian yang digunakan pada penelitian ini dengan mengadaptasi model ADDIE yang memiliki 5 tahapan antara lain analisis (analyze), desain (design), pengembangan (develop), implementasi (implement), dan evaluasi (evaluate). Adanya pembatasan pada penelitian yaitu hanya sampai pada uji kelayakan (validasi media dan materi) serta uji coba kemenarikan, maka peneliti mengadaptasi model ADDIE dengan membatasinya hanya pada tahap pengembangan (develop) karena tahap implement hingga evaluate sudah berada di fase penerapan atau penggunaan aplikasi pada proses pembelajaran yang sesungguhnya lalu dievaluasi kembali aplikasi program linear untuk menjadi media pendukung yang baik dalam mencapai tujuan pembelajaran (Feriatna, et. al., 2017).

Tahap analyze (analisis), tujuan dari fase analisis adalah untuk memvalidasi kemungkinan apa saja yang menjadi penyebab adanya kesenjangan kinerja pada proses pembelajaran. Dilakukan enam langkah yaitu analisis kesenjangan kinerja, menetapkan tujuan instruksional, mengidentifikasi karakteristik siswa, mengidentifikasi sumber daya, menentukan strategi penyampaian potensial, dan menyusun rencana kerja. Tahap selanjutnya yaitu design (desain) yang memiliki tujuan untuk memverifikasi kinerja yang diinginkan dan metode pengujian yang tepat. Terdapat empat prosedur di tahap desain antara lain melakukan inventaris tugas, menyusun tujuan pembelajaran, menghasilkan strategi pengujian, dan menghitung investasi. Tahap ketiga yaitu develop (pengembangan) yang bertujuan untuk memperoleh dan memvalidasi sumber daya pada pembelajaran yang dipilih. Tahap pengembangan memiliki beberapa langkah proseduralnya yaitu menghasilkan media pembelajaran, memilih atau mengembangkan media yang mendukung, mengembangkan panduan untuk siswa, mengembangkan panduan untuk guru, melakukan revisi formatif, melakukan uji coba kemenarikan (Branch, 2009). Prosedur Model ADDIE ini kemudian secara terperinci disajikan dalam Tabel $1 .$. Secara alurnya dapat dilihat dalam diagram model pengembangan ADDIE pada Gambar $1 .$. 
Tabel 1. Prosedur Model ADDIE

\begin{tabular}{ll}
\hline \multicolumn{1}{c}{ Fase } & \\
\hline Analyze (Analisis) & 1. Memvalidasi kesenjangan kinerja. \\
& 2. Menetapkan tujuan instruksional. \\
& 3. Mengidentifikasi karakteristik siswa. \\
& 4. Mengidentifikasi sumber daya yang relevan. \\
& 5. Menentukan Strategi Penyampaian Potensial. \\
& 6. Menyusun rencana kerja. \\
1. Mesign (Desain) & 2. Menyusun tujuan pembelajaran. \\
& 3. Menghasilkan strategi pengujian. \\
& 4. Menghitung investasi. \\
1. Menghasilkan media pembelajaran \\
(Pengembangan) & 2. Memilih atau mengembangkan media pendukung. \\
& 3. Mengembangkan panduan untuk siswa. \\
& 4. Mengembangkan panduan untuk guru. \\
& 5. Melakukan revisi formatif. \\
6. Melakukan uji coba. \\
1mplement & 1. Mempersiapkan guru. \\
Evaluate (Evaluasi) & 2. Mempersiapkan siswa. \\
& 2. Menentukan kriteria evaluasi. \\
& 3emilih alat evaluasi.
\end{tabular}

Sumber: Branch (2009)

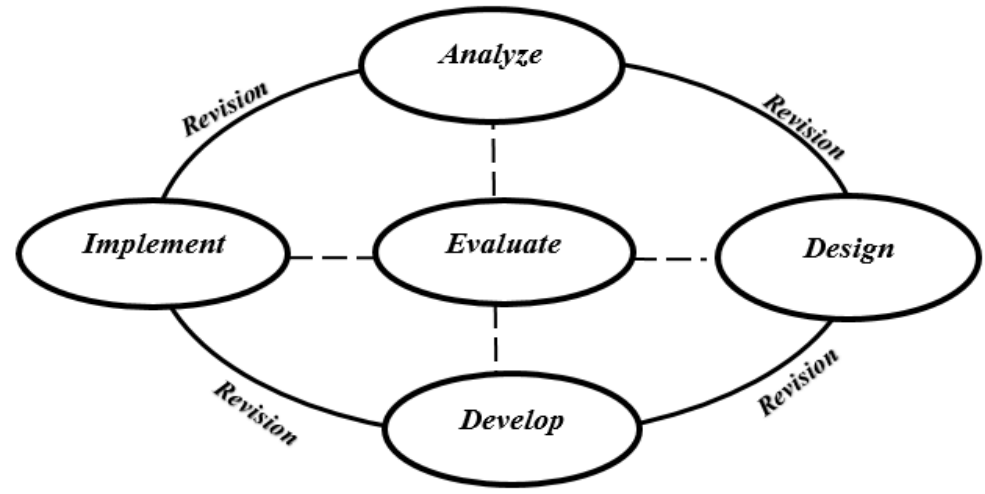

Gambar 1. Diagram Model Pengembangan ADDIE (Branch, 2009)

Tahap analyze (analisis), tujuan dari fase analisis adalah untuk memvalidasi kemungkinan apa saja yang menjadi penyebab adanya kesenjangan kinerja pada proses pembelajaran. Dilakukan enam langkah yaitu analisis kesenjangan kinerja, menetapkan tujuan instruksional, mengidentifikasi karakteristik siswa, mengidentifikasi sumber daya, menentukan strategi penyampaian potensial, dan menyusun rencana kerja. Tahap selanjutnya yaitu design (desain) yang memiliki tujuan untuk memverifikasi kinerja yang diinginkan dan metode pengujian yang tepat. Terdapat empat prosedur di tahap desain antara lain melakukan inventaris tugas, menyusun tujuan pembelajaran, menghasilkan strategi pengujian, dan menghitung investasi. Tahap ketiga yaitu develop (pengembangan) yang bertujuan untuk memperoleh dan memvalidasi sumber daya pada pembelajaran yang dipilih. Tahap pengembangan memiliki beberapa langkah proseduralnya yaitu menghasilkan media pembelajaran, memilih atau mengembangkan media yang mendukung, mengembangkan panduan untuk siswa, mengembangkan panduan untuk guru, melakukan revisi formatif, melakukan uji coba kemenarikan (Branch, 2009). 
Wawancara, angket validasi materi, angket validasi media, dan angket respon kemenarikan siswa digunakan sebagian instrumen pengumpulan data pada penelitian ini. Empat pilihan jawaban yang digunakan dalam angket validasi aplikasi adalah skor 4 Sangat Baik (SB), skor 3 Baik (B), skor 3 Cukup (C), skor 1 Kurang (K). Angket respon kemenarikan siswa terdapat empat pilihan jawaban juga dengan kriteria skor 4 Sangat Setuju (SS), 3 Setuju (S), 2 Tidak Setuju (TS), dan 1 Sangat Tidak Setuju (STS). Hasil dari analisis data yang diperoleh dihitung menggunakan rumus diadobsi dari penelitian terdahulu (Supardi, et. al., 2018), sebagai berikut:

$$
\bar{X}=\frac{\sum_{i=1}^{n} x_{i}}{n}
$$

dengan,

$$
x_{i}=\frac{\text { jumlah skor }}{\text { skor maksimal }} \times 4
$$

Keterangan:

$\bar{X} \quad$ : rata-rata akhir

$x_{i} \quad$ : nilai uji operasional angket tiap responden

$n$ : banyaknya responden yang mengisi angket

Setelah diperoleh skor dari responden baik dari validator maupun siswa, lalu dilakukan pengkonversian untuk dapat diklasifikasi dengan kriteria pada Tabel 2. untuk validator dan Tabel 3. untuk klasifikasi kemenarikan siswa.

Tabel 2. Skor Kriteria Validasi (Modifikasi)

\begin{tabular}{ccc}
\hline Skor Kualitas & Kriteria Kelayakan & Keterangan \\
\hline $3,26<\bar{X} \leq 4,00$ & Layak Digunakan & Tidak Revisi \\
$2,51<\bar{X} \leq 3,26$ & Cukup Layak Digunakan & Revisi Sebagian \\
& Kurang Layak & Revisi Sebagian dan \\
$1,76<\bar{X} \leq 2,51$ & Digunakan & Pengkajian Ulang \\
$1,00<\bar{X} \leq 1,76$ & Tidak Layak Digunakan & Revisi Total \\
\hline
\end{tabular}

Sumber: Supardi, et. al., (2018)

Tabel 3. Kriteria untuk Uji Kemenarikan (Modifikasi)

\begin{tabular}{cc}
\hline Skor Kualitas & Kriteria Kemenarikan \\
\hline $3,26<\bar{X} \leq 4,00$ & Sangat Menarik \\
$2,51<\bar{X} \leq 3,26$ & Menarik \\
$1,76<\bar{X} \leq 2,51$ & Kurang Menarik \\
$1,00 \leq \bar{X} \leq 1,76$ & Sangat Kurang menarik
\end{tabular}

Sumber: Supardi, et. al., (2018)

Subjek penelitian pada tahap uji coba dilaksanakan di SMK-SMTI (Sekolah Menengah Kejuruan Sekolah Menengah Teknologi Industri) Bandar Lampung pada kelas XI Kimia Industri dengan akumulasi total responden 35 siswa. 3 siswa dengan tingkat kemampuan berbeda yaitu tinggi, sedang, dan rendah pada uji coba perorangan. Uji coba kelompok kecil dengan kemampuan responden yang heterogen berjumlah 10 siswa. Uji coba lapangan dilakukan pada 22 siswa dengan kemampuan yang heterogen. Teknik pengumpulan data dilakukan dengan angket. Instrumen yang peneliti gunakan yaitu aplikasi program linear.

\section{HASIL}

Produk yang dihasilkan pada penelitian ini berupa aplikasi untuk smartphone berbasis android menggunakan MIT App Inventor untuk materi program linear kelas X SMK. Kecanggihan pada smartphone dengan memanfaatkan mobile apps dapat membantu siswa dan guru dalam proses 
pembelajaran (Sholeh, et. al., 2021). Langkah-langkah yang dilakukan guna terealisasikannya tujuan dari penelitian ini sebagai berikut:

1. Analyze

a. Memvalidasi kesenjangan kinerja

Beberapa hal yang dihasilkan dari observasi untuk langkah ini yaitu guru belum menggunakan media pembelajaran yang bervariasi selain buku paket sehingga siswa juga hanya terpaku pada buku paket sebagai sumber belajar sedangkan mayoritas siswa menjadi pengguna aktif smartphone android.

b. Menetapkan tujuan instruksional

Tujuan instruksional yang ditetapkan adalah mengembangkan media pembelajaran berupa aplikasi android berbantuan MIT App Inventor guna menunjang media pembelajaran yang lebih bervariasi dan pemanfaatan smartphone yang lebih positif bagi siswa.

c. Mengidentifikasi karakteristik siswa

Hasil dari pengidentifikasian karakteristik siswa meliputi:

1) Kebanyakan siswa masih pasif dalam kegiatan pembelajaran matematika.

2) Siswa kurang teliti dalam memahami konsep rumus-rumus.

3) Pemanfaatan smartphone secara maksimal guna menunjang proses pembelajaran.

4) Kemampuan penalaran siswa yang masih kurang.

d. Mengidentifikasi sumber daya yang relevan

Hasil dari langkah pengidentifikasian sumber daya yang tersedia antara lain:

1) Sumber daya isi

Sumber daya isi meliputi buku yang digunakan siswa dan guru pada pembelajaran matematika kelas X SMK dan juga RPP Kurikulum 2013.

2) Sumber daya teknologi

Adapun sumber daya teknologi yang tersedia LCD proyektor yang disediakan di setiap kelas, komputer, dan lain-lain namun adanya pandemi global membuat siswa belum bisa menggunakannya dalam pembelajaran.

3) Fasilitas Instruksional

Fasilitas yang dibutuhkan pada proses penelitian serta jadwal mata pelajaran menjadi fasilitas instruksional pembelajaran di penelitian ini.

4) Sumber daya manusia

Peneliti, guru matematika, siswa, ahli materi, dan ahli media.

e. Menentukan strategi penyampaian potensial

Pertemuan tatap muka secara fisik dipilih sebagai alternatif sistem penyampaian. Peneliti menjelaskan bagaimana cara penggunaan aplikasi agar penggunaannya dapat maksimal dan sekaligus menyebar angket kemenarikan pada siswa. Penyampaian aplikasi kepada user dapat mengakses play store melalui link https://bit.ly/ProglinSyrfh agar lebih cepat atau search langsung di play store dengan keyword Studio Kite Lab: Program Linear.

f. Menyusun Rencana Kerja

Manajemen rencana kerja proses pengembangan aplikasi program linear disusun sesuai dengan tahapan ADDIE dan estimasi waktu menyesuaikan dengan kebutuhan.

2. Design

a. Melakukan inventaris tugas

Adapun hasil dari pengidentifikasian meliputi pokok materi pada bab program linear, video pembelajaran, kumpulan soal untuk kuis dan evaluasi beserta kunci jawabannya, aset desain untuk produk seperti 1) logo aplikasi; 2) ikon-ikon untuk tampilan menu utama; 3) background aplikasi, dan prototypelstoryboard.

b. Menyusun tujuan pembelajaran

Tujuan pembelajaran diadaptasi pada kurikulum yang digunakan yaitu:

1) Memahami konsep program linear 
2) Menyusun model matematika dari masalah kontekstual yang berkaitan dengan program linear dua variabel

3) Menentukan nilai maksimum dan minimum permasalahan kontekstual yang berkaitan dengan program linear dua variabel

4) Menggambar grafik himpunan penyelesaian dari permasalahan kontekstual yang berkaitan dengan program linear dua variabel

5) Menyelesaikan masalah kontekstual yang berkaitan dengan program linear dua variabel.

c. Menghasilkan strategi pengujian

Strategi pengujian yang digunakan meliputi angket yang berfungsi untuk menilai kualitas dari aplikasi android program linear oleh para validator ahli media, ahli materi, dan guru serta angket kemenarikan untuk dinilai siswa.

d. Menghitung investasi

Investasi biaya yang diperlukan peneliti hanya untuk biaya jasa publish aplikasi di playstore.

3. Develop

a. Menghasilkan media pembelajaran

Media pembelajaran yang dihasilkan sesuai dengan prototipe yang dirancang pada tahap desain. Aplikasi memuat splash screen (Gambar 2.) di tampilan awal dengan periode waktu 3 detik lalu langsung mengarah ke halaman menu utama (Gambar 3.). Menu utama terdiri dari enam button yaitu KD \& IPK (Gambar 4.), materi (Gambar 5.), kuis (Gambar 6., Gambar 7., dan Gambar 8.), video (Gambar 9.), evaluasi (Gambar 10.), dan informasi (Gambar 11.).

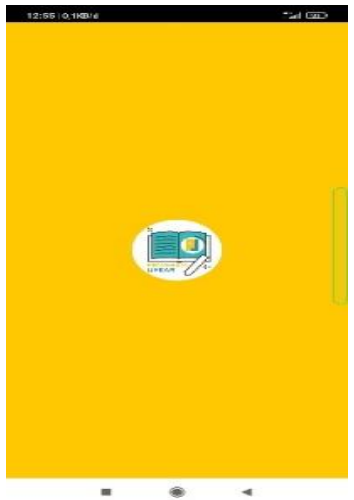

Gambar 2. Tampilan Splash Screen

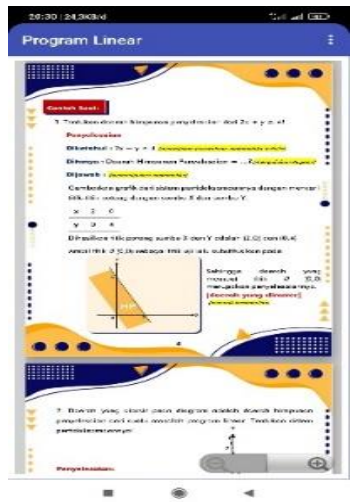

Gambar 5. Tampilan Materi

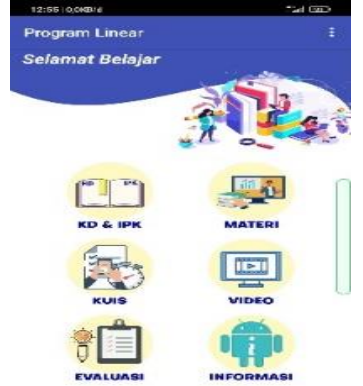

Gambar 3. Tampilan Menu Utama

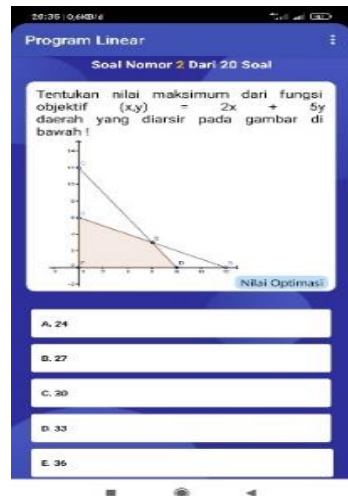

Gambar 6. Tampilan Kuis

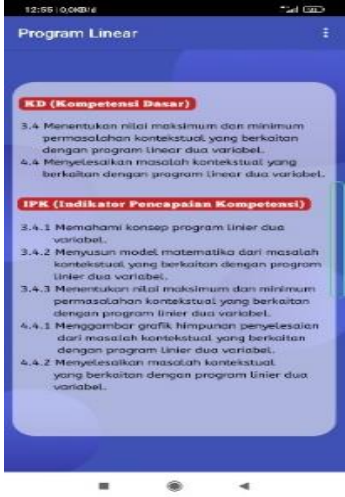

Gambar 4. Tampilan KD dan IPK

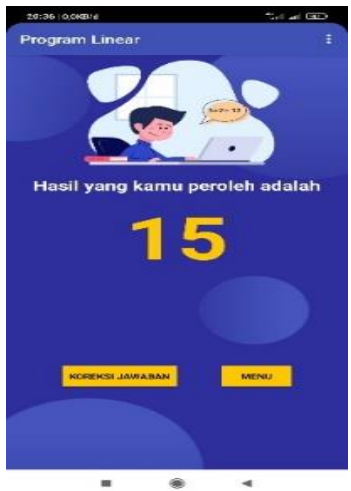

Gambar 7. Tampilan Hasil Kuis 


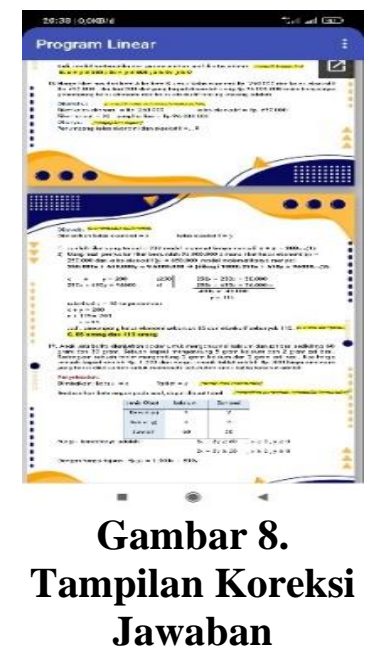

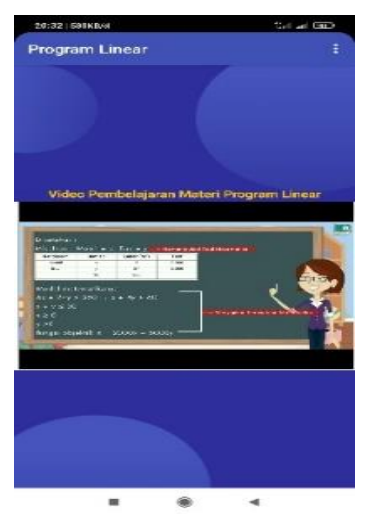

Gambar 9. Tampilan

Video Pembelajaran

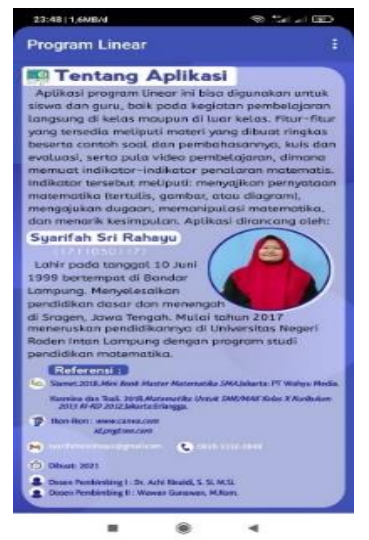

Gambar 11. Tampilan

Informasi

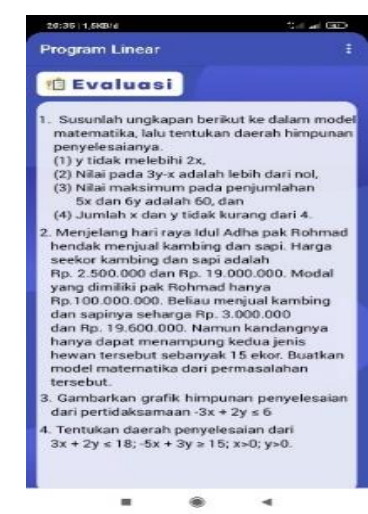

Gambar 10. Tampilan Evaluasi

Button KD \& IPK memuat kompetensi dasar dan indikator pencapaian kompetensi siswa yang telah disesuaikan pada Kurikulum 2013. Halaman materi berisi materi program linear yang dibuat ringkas dan contoh soal beserta cara penyelesaiannya. Side kuis berisi kumpulan soal pilihan ganda program linear yang dirancang acak dan langsung keluar skor yang kita peroleh setelah menyelesaikan soal-soal. Terdapat pilihan koreksi jawaban pada halaman perolehan skor yang bisa digunakan untuk mengevaluasi kembali jawaban yang telah dipilih.

Halaman video memuat video pembelajaran materi program linear. Halaman evaluasi menampilkan soal-soal yang bisa digunakan untuk berlatih mengasah pemahaman pada materi program linear. Terakhir adalah halaman informasi yang menampilkan profil perancang serta sumber-sumber yang digunakan dalam merancang aplikasi.

b. Memilih atau mengembangkan media pendukung

Media pembelajaran ini didukung video pembelajaran di dalamnya, diharapkan agar siswa tertarik dan lebih semangat dalam belajar.

c. Mengembangkan panduan untuk siswa

Panduan untuk siswa berupa pedoman yang digunakan dalam pengoperasian aplikasi.

d. Mengembangkan panduan untuk guru

Panduan untuk guru tidak jauh berbeda dengan pedoman yang digunakan untuk siswa, guru diberi akses untuk mengembangkan aplikasi.

e. Melakukan revisi formatif

Revisi formatif dilakukan oleh validator ahli materi dan media. Adapun revisi yang diberikan oleh ahli media yaitu perubahan warna yang kontras dengan warna background pada soal evaluasi dari warna ungu menjadi hitam, validator juga memberi saran agar kunci 
jawaban dicantumkan lalu peneliti merevisi dengan mencantumkan kunci jawaban semua soal. Di samping itu ahli materi juga memberi revisi agar kalimat tipo lebih diperhatikan sesuai kaidah dan ejaan yang disempurnakan dalam bahasa Indonesia, pemodelan matematika di contoh soal diganti dengan soal yang bernuansa Islami, dan penyesuaian urutan soal pada halaman evaluasi agar disesuaikan dengan IPK (Indikator Pencapaian Kompetensi).

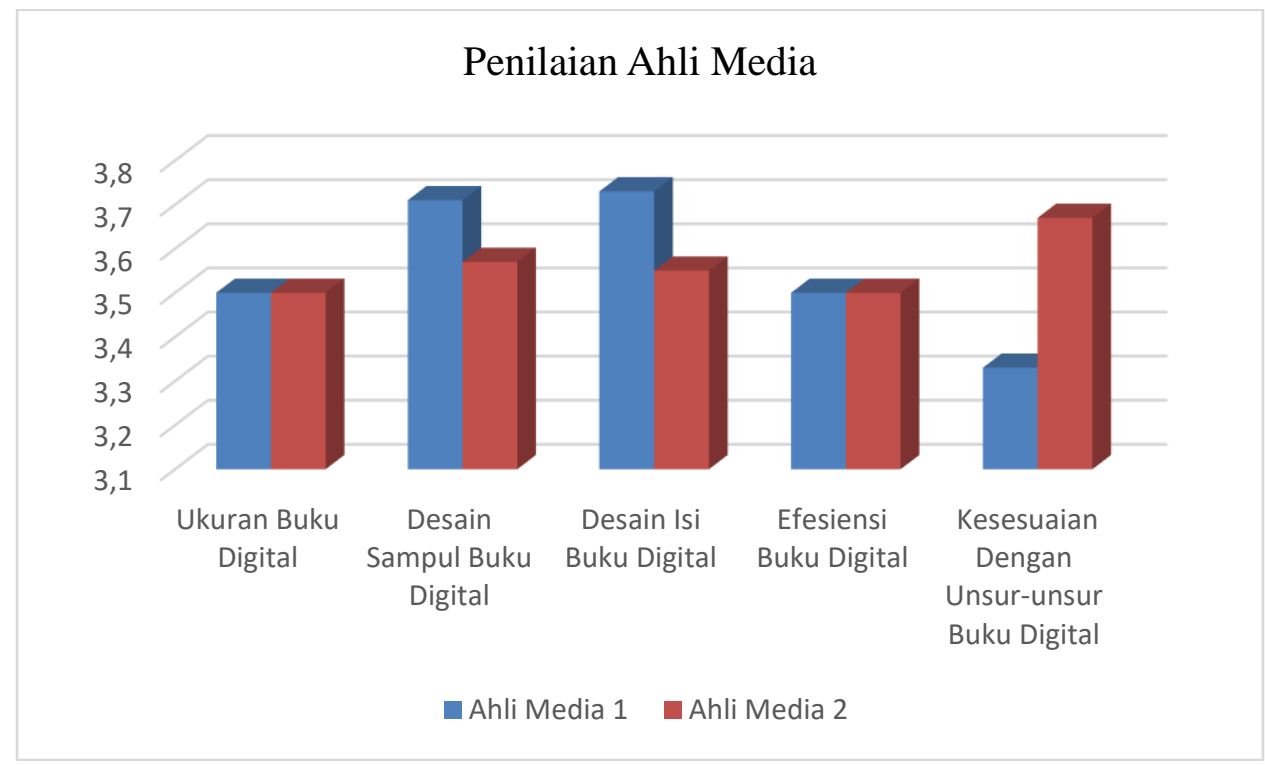

Gambar 12. Hasil Penilaian Ahli Media

Gambar 12. menunjukkan hasil penilaian dari kedua ahli media pada lima aspek yang dinilai yaitu dari aspek ukuran, desain sampul, desain isi, efisiensi, dan kesesuaian unsurunsur dari buku digital dengan perolehan nilai rata-rata 3,56 memasuki kualifikasi valid dan layak digunakan.

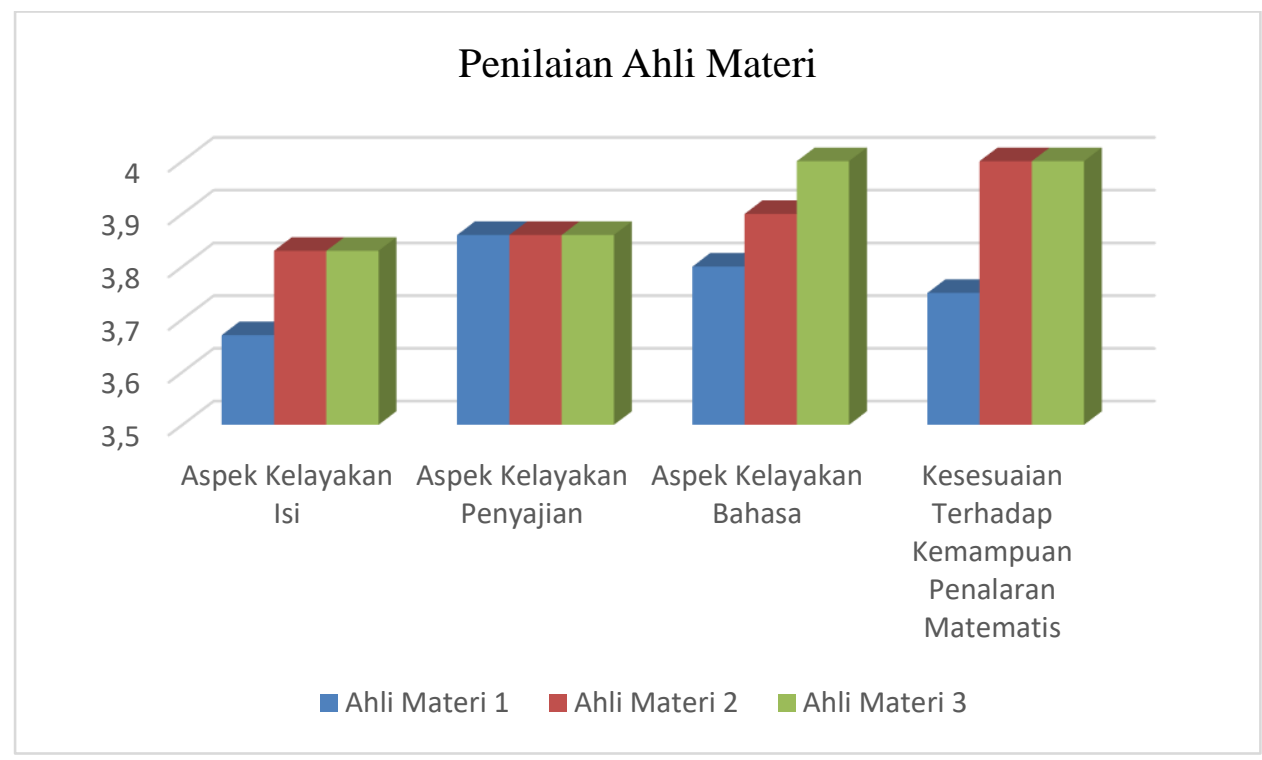

Gambar 13. Hasil Penilaian Ahli Materi

Gambar 13. menunjukan hasil penilaian dari ketiga ahli materi pada empat aspek yang dinilai yaitu aspek kelayakan isi, penyajian, bahasa, dan kesesuaian pada kemampuan penalaran matematis dengan perolehan nilai rata-rata 3,86 memasuki kualifikasi valid sehingga layak digunakan. 
f. Melakukan uji coba

Uji coba yang dilakukan adalah uji coba kemenarikan, dilakukan pada siswa sebagai subjek uji coba atau responden. Uji coba perorangan (one to one trial) pada tiga orang siswa yang memiliki tingkat kemampuan yang berbeda yaitu tinggi, sedang, dan rendah memperoleh skor rata-rata 3,50. Uji coba kelompok kecil (small group trial) dan uji coba lapangan (field trial) dilakukan pada siswa yang memiliki kemampuan yang heterogen sebanyak sepuluh dan dua puluh dua responden dengan nilai hasil rata-rata 3,55 dan 3,58. Hasil dari ketiga uji coba tersebut termasuk pada kriteria interpretasi "Sangat Menarik".

\section{PEMBAHASAN}

Pengembangan media pembelajaran memiliki banyak peran dalam pemanfaatan teknologi sebagai bentuk upaya pendukung kelancaran untuk terwujudnya tujuan dari pembelajaran. Materi program linear pada jenjang Sekolah Lanjut Tingkat Atas (SLTA) sebelumnya telah dikembangkan beragam bentuk mulai dari LKS (Lembar Kerja Siswa), e-comic, PowerPoint, dan masih banyak lagi namun belum ada yang mengembangkan menggunakan MIT App Inventor (Fannie \& Rohati, 2014; Hermawan, et. al., 2018; Rizki \& Linuhung, 2016). MIT App Inventor merupakan builder aplikasi android yang dapat membuat bermacam aplikasi antara lain game bola tangkis, aplikasi E-business Cooperation sehingga multi-produsen dapat memasarkan serta mengawasi barang produksi, aplikasi kamus akuntansi, aplikasi pembelajaran psikotes, game edukasi untuk TK dan PAUD guna memacu sensorik dan motorik anak, (Effendi, 2018; Hamdi \& Krisnawati, 2011; Hasan, et. al., 2017; Yaqin \& Al Anis, 2019) dan tidak hanya itu dalam bidang pendidikan MIT App Inventor dapat digunakan untuk membuat aplikasi dengan cakupan materi matematika seperti barisan dan deret, trigonometri, aljabar, geometri, sistem operasi, dan fungsi komposisi (Angriani, et. al., 2020; Ekiningsih, et. al., 2019; Fitri, et. al., 2021; Hakky, et. al., 2018; Negara, et. al., 2019) dari sekian banyak materi belum ditemukan materi program linear untuk tingkatan pendidikan SMK. Selain dari pemaparan tersebut, keterbaruan lainnya dari penelitian ini dibandingkan penelitian sebelumnya yaitu aplikasi program linear sudah dapat diunduh secara universal dan gratis di playstore melalui link https://bit.ly/ProglinSyrfh atau search langsung di play store dengan kata kunci Studio Kite Lab: Program Linear.

Aplikasi program linear dikembangkan dengan mengadaptasi model penelitian pengembangan ADDIE (Analyze, Design, Develop, Implement, Evaluate). Penelitian ini menguji kelayakan media dan respon siswa terhadap media aplikasi program linear, dimana pada tahap ADDIE hanya sebatas pada langkah develop (pengembangan). Langkah awal yaitu analyze (analisis), langkah ini dilakukan agar mengetahui gap apa saja yang ada pada kegiatan pembelajaran sekaligus menentukan jalan keluar dari kesenjangan yang ada. Langkah design menjadi tahap perancangan dalam hal ini perancangan aplikasi program linear, baik perancangan dari investasi yang diperlukan, tampilan, isi, hingga pengujian aplikasi yang dilakukan pada tahap develop nantinya.

Tahap develop menjadi langkah eksekusi dari rancangan yang telah dibuat di tahap design sebelumnya. Aset-aset desain, materi, soal-soal, dan video yang akan ditampilkan menjadi sebuah aplikasi dirakit dengan kode program menjadi aplikasi program linear. Setelah aplikasi jadi lalu melewati fase revisi oleh para pakar media dan materi. Uji validasi oleh ahli media mendapat skor rata-rata 3,56 dan ahli materi 3,86 dengan kriteria interpretasi valid sehingga layak untuk digunakan. Setelah itu media diuji respon kemenarikannya pada siswa, pada uji perorangan mendapat nilai dengan range 3,50, uji coba kelompok kecil 3,55, dan uji coba lapangan 3,58 dan ketiganya menempati skor rata-rata dengan kualifikasi sangat menarik.

Kelebihan dari aplikasi android program linear ini yaitu dapat digunakan kapan dan dimana saja sehingga fleksibel untuk belajar pada kegiatan pembelajaran di kelas maupun di rumah. Dilengkapi dengan video pembelajaran pembahasan soal program linear. Kekurangan dari aplikasi ini yaitu ada beberapa fitur seperti materi, kunci jawaban soal-soal, dan video yang harus diakses 
menggunakan data internet. Video dan materi yang hanya terbatas pada program linear. Sedangkan kekurangan dari MIT App Inventor adalah belum dapat digunakan membuatan aplikasi untuk iPhone, dalam pembuatan tampilan peneliti dituntut kreatif dan memperhitungkan dengan tepat dalam pembuatan tampilan yang menarik, karena tidak disediakan fitur tampilan yang otomatis dan tampilan di smartphopne satu dengan yang lain terkadang berbeda karena dipengaruhi ukuran smartphone yang berbeda pula.

\section{SIMPULAN}

Berdasarkan hasil dari analisis dan pembahasan yang telah dilakukan peneliti, maka dapat ditarik simpulan media pembelajaran berbentuk aplikasi program linear berbantuan MIT App Inventor dalam kategori layak untuk digunakan serta menempati kualifikasi yang menarik. Perolehan skor dari ahli materi dihasilkan nilai rata-rata 3,86 dan ahli media sebesar 3,56. Uji kemenarikan diperoleh nilai rata-rata 3,50 pada uji coba perorangan, 3,55 pada uji coba kelompok kecil, dan 3,58 pada uji coba lapangan.

\section{DAFTAR RUJUKAN}

Angriani, A. D., Kusumayanti, A., \& Nur, F. (2020). Pengembangan Media Pembelajaran MathSC Berbasis Android Menggunakan App Inventor 2 pada Materi Barisan dan Deret Aritmatika. Jurnal Cendekia: Jurnal Pendidikan Matematika, 4(2), 926-938. https://doi.org/https://doi.org/10.31004/cendekia.v4i2.322

Apriliyani, S. W., \& Mulyatna, F. (2021). Flipbook E-LKPD dengan Pendekatan Etnomatematika pada Materi Teorema Phytagoras. Prosiding Seminar Nasional Sains, 2(1), 491-500. http://www.proceeding.unindra.ac.id/index.php/sinasis/article/view/5389

Branch, R. M. (2009). Instructional design: The ADDIE approach. Springer Science \& Business Media, LCC. https://doi.org/10.1007/978-0-387-09506-6

Effendi, Y. (2018). Rancangan Aplikasi Game Edukasi Berbasis Mobile Menggunakan App Inventor. Jurnal Intra-Tech, 2(1), 39-48. https://www.journal.amikmahaputra.ac.id/index.php/JIT/article/view/24

Ekiningsih, E., Buchori, A., \& Albab, I. U. (2019). Pengembangan Media Pembelajaran Mobile Learning Dengan Pendekatan PMRI Pada Materi Fungsi Komposisi di SMK. Seminar Nasional Matematika Dan Pendidikan Matematika, 4, 246-255. http://conference.upgris.ac.id/index.php/senatik/article/view/64

Fannie, R. D., \& Rohati, R. (2014). Pengembangan Lembar Kerja Siswa (Lks) Berbasis Poe (Predict, Observe, Explain) Pada Materi Program Linear Kelas XII SMA. Sainmatika: Jurnal Sains Dan Matematika Universitas Jambi, 8(1), 96-109.

Feriatna, T., Pramuditya, S. A., \& Aminah, N. (2017). PENGEMBANGAN APLIKASI ANDROID SEBAGAI MEDIA PEMBELAJARAN MATEMATIKA PADA MATERI PELUANG UNTUK SISWA SMA KELAS X. LEMMA, IV(1), 65-75.

Fitri, F., Lamada, M. S., \& Zulhajji, Z. (2021). Pengembangan Media Pembelajaran Matematika Menggunakan Mit App Inventor di SMKN 2 Wajo. Jurnal MediaTIK, 4(1), 1-4. https://doi.org/10.26858/jmtik.v4i1.19720

Hakky, M. K., Wirasasmita, R. H., \& Uska, M. Z. (2018). Pengembangan Media Pembelajaran Berbasis Android untuk Siswa Kelas X Pada Mata Pelajaran Sistem Operasi. EDUMATIC: Jurnal Pendidikan Informatika, 24-33. https://doi.org/https://doi.org/10.29408/edumatic.v2i1.868

Hamdi, G., \& Krisnawati, K. (2011). Membangun Aplikasi Berbasis Android "Pembelajaran Psikotes" Menggunakan App Inventor. Jurnal Dasi, 12(4), 37-41. https://ojs.amikom.ac.id/index.php/dasi/article/view/78 
Hasan, M. A., Nasution, N., \& Setiawan, D. (2017). Game Bola Tangkis Berbasis Android Menggunakan App Inventor. Digital Zone: Jurnal Teknologi Informasi Dan Komunikasi, 8(2), 160-169. https://doi.org/https://doi.org/10.31849/digitalzone.v8i2.641

Hermawan, L. I., Hobri, H., Murtikusuma, R. P., Setiawani, S., \& Yudianto, E. (2018). Pengembangan E-Comic Berbantuan Pixton Pada Materi Program Linear Dua Variabel. Kadikma, 9(2), 78-88. https://doi.org/https://doi.org/10.19184/kdma.v9i2.9748

Komputer, W. (2013). Pemrograman Android dengan APP INVENTOR (1st ed.). Yogyakarta: Andi Publisher.

Lestari, I. D. (2018). Peranan Guru dalam Penggunaan Media Pembelajaran Berbasis Information and Communication Technology (ICT) di SDN RRI Cisalak. SAP (Susunan Artikel Pendidikan), 3(2), 137-142. https://doi.org/http://dx.doi.org/10.30998/sap.v3i2.3033

Malenda, T. O., Kadir, K., \& Suhar, S. (2018). Kemampuan Numerik Siswa SMP Pesisir Ditinjau Dari Perbedaan Jenis Kelamin dan Kemandirian Belajar Siswa SMP Negeri 14 Kendari. Jurnal Penelitian Pendidikan Matematika, 6(3), 71-84. https://doi.org/http://dx.doi.org/10.36709/jppm.v6i3.9141

Marpaung, J. (2018). Pengaruh Penggunaan Gadget dalam Kehidupan. KOPASTA: Jurnal Program Studi Bimbingan Konseling, 5(2), 55-64. https://doi.org/https://doi.org/10.33373/kop.v5i2.1521

Mulyana, E. (2012). App Inventor: Ciptakan Sendiri Aplikasi Androidmu. Yogyakarta: Andi Publisher.

Mustaqim, I. (2016). Pemanfaatan Augmented Reality Sebagai Media Pembelajaran. Jurnal Pendidikan Teknologi Dan Kejuruan (JPTK), 13(2), 174-183. https://doi.org/http://dx.doi.org/10.23887/jptk-undiksha.v13i2.8525

Negara, H. R. P., Syaharuddin, S., Kurniawati, K. R. A., Mandailina, V., \& Santosa, F. H. (2019). Meningkatkan Minat Belajar Siswa Melalui Pemanfaatan Media Belajar Berbasis Android Menggunakan Mit App Inventor. SELAPARANG Jurnal Pengabdian Masyarakat Berkemajuan, 2(2), 42-45. https://doi.org/10.31764/jpmb.v2i2.887

Rizki, S., \& Linuhung, N. (2016). Pengembangan Bahan Ajar Program Linear Berbasis Kontekstual Dan Ict. AKSIOMA Journal of Mathematics Education, 5(2), 137-144. https://doi.org/10.24127/ajpm.v5i2.674

Safitri, W. Y., Haryanto, H., \& Rofiki, I. (2020). Integrasi Matematika, Nilai-Nilai Keislaman, dan Teknologi: Fenomena di Madrasah Tsanawiyah. Jurnal Tadris Matematika, 3(1), 89-104. https://doi.org/10.21274/jtm.2020.3.1.89-104

Septiyani, E., \& Apriyanto, M. T. (2019). Pengembangan Media Pembelajaran Matematika Berbasis Android untuk Tingkat SMP. JKPM (Jurnal Kajian Pendidikan Matematika), 5(1), 153-164. https://doi.org/10.30998/jkpm.v5i1.5230

Sholeh, M., Supriadi, N., \& Suherman, S. (2021). Etnomatematika pada Buku Saku Digital Berbasis Android Materi Segitiga dan Segiempat MTs. JKPM (Jurnal Kajian Pendidikan Matematika), 6(2), 191-204. https://doi.org/10.30998/jkpm.v6i2.9184

Supardi, N., Rinaldi, A., \& Rakhmawati M, R. (2018). Lembar Kerja Peserta Didik Berbasis Kegiatan Transaksi Kewirausahaan Materi Sistem Persamaan Linier Dua Variabel. Desimal: Jurnal Matematika, 1(1), 49. https://doi.org/10.24042/djm.v1i1.2012

Syaputrizal, N., \& Jannah, R. (2019). Media Pembelajaran Fisika Berbasis Mobile Learning pada Platform Android Menggunakan Aplikasi App Inventor untuk Meningkatkan Kemandirian Belajar Peserta Didik. Natural Science: Jurnal Penelitian Bidang IPA Dan Pendidikan IPA, 5(1), 800-809. https://ejournal.uinib.ac.id/jurnal/index.php/naturalscience/article/view/901/0

Tafonao, T. (2018). Peranan Media Pembelajaran Dalam Meningkatkan Minat Belajar Mahasiswa. Jurnal Komunikasi Pendidikan, 2(2), 103-114. https://doi.org/10.32585/jkp.v2i2.113

Wihidayat, E. S., \& Maryono, D. (2017). Pengembangan Aplikasi Android Menggunakan Integrated Development Environment (IDE) App Inventor 2. Jurnal Ilmiah Edutic: Pendidikan Dan Informatika, 4(1), 1-12. https://doi.org/https://doi.org/10.21107/edutic.v4i1.3229 
Wiratomo, Y., \& Mulyatna, F. (2020). Use of Learning Management Systems in Mathematics Learning during a Pandemic. Journal of Mathematical Pedagogy (JoMP), 1(2), 62-71. https://doi.org/https://doi.org/10.26740/jomp.v1n2.p\%25p

Yaqin, M. A., \& Al Anis, A. (2019). E-Business Cooperation Dalam Pemanfaatkan Media Mit App Inventor dan Web Bootstrap Sebagai Platform Untuk Meningkatkan Kesejahteraan Masyarakat Probolinggo. Teknika: Engineering and Sains Journal, 3(1), 13-18. https://doi.org/http://dx.doi.org/10.51804/tesj.v3i1.401.13-18 
120 Rahayu, Rinaldi, \& Gunawan

JKPM (Jurnal Kajian Pendidikan Matematika) Vol.7, No.1 (2021) 